\title{
DECORACIONES ARQUITECTÓNICAS DEL TARDOGÓTICO DE BURGOS Y SU INFLUENCIA EN ANDALUCÍA, PORTUGAL Y LA INDIA
}

\author{
RAÚl ROMERO MEDINA \\ UNIR-UNIVERSIDAD INTERNACIONAL DE LA RIOJA \\ MANUEL RoMERo BEJARANO \\ UNIVERSIDAD DE SEVILLA
}

RESUMEN: Las formas decorativas del tardogótico burgalés van a difundirse no solo en la arquitectura hispánica (Andalucía principalmente) sino en las obras de Portugal, gracias a la movilidad que experimentan los maestros canteros. De allí van a pasar a la India en un momento en el que su estado y capital están bajo la influencia lusa. Este artículo analiza la difusión de estas obras en Andalucía, Portugal y la India.

PALABRAS CLAVE: Tardogótico de Burgos, arquitectura hispánica, Andalucía, Portugal, India

\section{BURGOS LATE GOTHIC ARCHITECTURAL DECORATIONS AND THEIR INFLUENCE IN ANDALUSIA, PORTUGAL AND INDIA}

\begin{abstract}
The decorative forms of the late gothic of Burgos will spread not only in the Spanish architecture (primarily Andalusia) but in works of Portugal, thanks to mobility experienced by the stonemasons. From there they will go to India when it was the Portuguese influence. This paper examines the diffusion of these works in Andalusia, Portugal and India.
\end{abstract}

KEYWORDS: Late Gothic of Burgos, Spanish architecture, Andalusia, Portugal, India

Recibido: 19/01/2016/Aceptado: 27/03/2016 


\section{INTRODUCCIÓN}

A comienzos del siglo XVI la movilidad de los maestros constructores en la Península Ibérica fue una de las características fundamentales de la arquitectura de la época ${ }^{1}$. Canteros vascos y trasmeranos trabajaron en los principales focos artísticos y son conocidas las incursiones de los artífices burgaleses y toledanos en otras regiones, como la pujante Andalucía ${ }^{2}$. Portugal asumió las experiencias estéticas castellanas, a las que sumó otras traídas desde Aragón ${ }^{3}$, zona en la que el tardogótico tuvo un desarrollo muy destacado ${ }^{4}$. Así, no es de extrañar que encontremos elementos constructivos y ornamentales muy similares en puntos muy lejanos incluso hoy día, en que las comunicaciones han acortado de modo significativo las distancias, mucho más en un periodo en que los desplazamientos se hacían a caballo o en barco.

\section{UN PUNTO DE PARTIDA AL FINAL DEL CAMINO. EL BAPTISTERIO DE SAN MIGUEL DE JEREZ DE LA FRONTERA}

Vamos a centrarnos en un tipo de decoración de vano un tanto peculiar que aparece en la puerta de la capilla bautismal de San Miguel de Jerez de la Frontera (Ilustración no 1). El vano es un arco carpanel que apoya sobre estrechas ménsulas decoradas con bandas vegetales. Este arco en el exterior presenta una banda decorada con motivos florales aislados, unas flores alargadas con cuatro hojas que recuerdan al acanto, mientras que la zona interior del arco presenta una banda continua de motivos vegetales. Justo en la embocadura del arco, en la zona interior de la capilla, hallamos una estrecha estructura helicoidal que la recorre de arriba abajo formada por bandas alternas de cascabeles y un motivo de cuerda anudada. Al exterior, el arco carpanel queda coronado por una estructura pentagonal mixtilínea que resulta una especie de gablete formado por cuatro molduras semicirculares, decoradas en su parte exterior con cardinas y en su interior por las mismas flores con hojas similares al cardo que encontramos en el arco carpanel, que dividen en cuatro la zona superior de la portada. En el centro de los espacios inferiores, cuyo

\footnotetext{
1 ALONSO RUIZ, Begoña, “Los tiempos y los nombres del tardogótico castellano”, en Begoña Alonso Ruiz (ed.): La arquitectura tardogótica entre Europa y América. Actas del Congreso, Madrid, 2011, pp. 43-79.

2 RODRÍGUEZ ESTÉVEZ, Juan Clemente, "El tardogótico del sur: Andalucía y Canarias", en Begoña Alonso Ruiz (ed.): op. cit., pp. 81-109.

3 NUNES DA SILVA, Ricardo, “Os arquitectos e a arquitectura tardo-gotica em Portugal", en Begoña Alonso Ruiz (ed.): op. cit., pp. 503-539.

4 SERRA DESFILIS, Amadeo, "La arquitectura del tardogótico en la Corona de Aragón: intercambios y trayectorias”, en Begoña Alonso Ruiz (ed.): op. cit., pp. 449-490.
} 
abigarramiento decorativo se ve reforzado por una cardina, hallamos una rosa. En la zona superior cada uno los espacios superiores hay cuatro rosas, alineadas con la moldura que remata la portada, que es muy estrecha y se halla decorada con una línea de motivos vegetales que se alternan con otros similares a garras. Los vértices de la estructura pentagonal quedan rematados por un copete vegetal trilobulado, mientras que en el interior de la estructura hallamos el escudo de la parroquia y bajo él, y dentro de una corona de laurel, un escudo cardenalicio con el campo liso. En concreto nos interesa el peculiar gablete pentagonal, que aparece en otras obras que pasaremos a reseñar, pero antes hay que hacer referencia a la datación de la portada jerezana.

El primero que estudió en profundidad este baptisterio fue Hipólito Sancho, quien la relacionó con el cardenal Cisneros en una enrevesada argumentación históricoartística. Entre las razones estéticas el historiador portuense señala la similitud de esta obra con otras realizadas bajo el patrocinio de los Reyes Católicos, como son la fachada de la iglesia del monasterio de Santa Cruz de Segovia, la fachada de la iglesia del monasterio de Santo Tomás en Ávila, "alguna [portada] de San Juan de los Reyes de Toledo y el antiguo palacio ducal de Torrijos entre otros", correlatos que no parecen tan evidentes si no es dentro del marco general de la arquitectura tardogótica castellana. Pero ahí no queda la cosa, ya que Sancho se refiere sin pudor a "la armonía existente entre la arquitectura de las obras del cardenal dirigidas por su alarife Gumiel y esta portada del baptisterio de San Miguel" . Cualquiera que conozca el Paraninfo de la Universidad de Alcalá de Henares o las dependencias capitulares de la catedral de Toledo podrá comprobar que dicha armonía no existe. Además, la aparición del motivo del cordón anudado en la embocadura del arco, presente en otras obras patrocinadas por Cisneros, le sirve a Sancho para reforzar sus teorías. Pero lo grave no es su despiste al relacionar edificios, sino que inventa una serie de documentos para justificar la relación del Cardenal con Jerez, algo inexistente a tenor de la biografía más rigurosa que se ha escrito sobre este destacado personaje histórico ${ }^{6}$.

Recientes investigaciones han datado esta portada, al igual que buena parte del templo en que se ubica, en la década de los 20 del XVI, poniéndola en relación tanto con Juan Gil de Hontañón como con los maestros portugueses que trabajaron en la Baja

\footnotetext{
${ }^{5}$ SANCHO DE SOPRANIS, Hipólito, Introducción al estudio de la arquitectura en Xerez, Guión, Jerez de la Frontera, 1934, pp. 61 y ss.

${ }^{6}$ GARCÍA ORO, José, El Cardenal Cisneros. Vida y empresas, Madrid, Biblioteca de Autores Cristianos, 1992. tomo I, pp. 3 y ss.
} 
Andalucía en ese momento, ya que en la obra aparecen motivos tales como la soga o los cascabeles, característicos del tardogótico luso ${ }^{7}$.

Sin embargo, el motivo ornamental que nos interesa no aparece en la obra jerezana por primera vez, de hecho se trata de una de las últimas veces en que se utiliza, así que hemos de analizar el origen de tan peculiar forma.

\section{LA AVENTURA CASTELLANA. DESDE BURGOS A ALMERÍA}

El modelo de la portada de la capilla bautismal de San Miguel tiene su origen en algunas sillerías de coro de finales del XV y comienzos del XVI, como las de las catedrales de Plasencia $^{8}$, Ciudad Rodrigo ${ }^{9}$ y Coria ${ }^{10}$ (Ilustración $n^{\circ} 2$ ) y en el retablo mayor de la catedral de Toledo, cuya construcción comenzó en 1499 según las trazas de Enrique Egas ${ }^{11}$. En la obra del propio Egas encontramos soluciones similares, por ejemplo en el monumento funerario de Alfonso VII de la catedral de Toledo o en alguna de las portadas del Hospital de Santa Cruz de la misma ciudad, e incluso en la capilla Real de Granada ${ }^{12}$, donde aparece en las dos portadas. Sin embargo, en todas las obras citadas el elemento presenta una mayor anchura y en casi todos los casos aparece acompañado de una compleja tracería. Su eco se deja sentir en otras obras del entorno, como la parroquia de la Asunción de Tembleque, la capilla del Encaje de la iglesia de San Pablo de Úbeda o la portada del convento de Santa Isabel de Granada.

No obstante, el elemento que hemos identificado aparece por primera vez en arquitectura en tierras burgalesas en las portadas de las parroquias de Melgar de Fernamental (Ilustración no 3 ) y Villahoz, en las que trabajó Francisco de Colonia en la primera década del XVI ${ }^{13}$. La cronología de ambos templos es un tanto imprecisa, y tan

\footnotetext{
${ }^{7}$ ROMERO BEJARANO, Manuel, Maestros y obras de ascendencia portuguesa en el tardogótico de la Baja Andalucia, Tesis Doctoral inédita. Sevilla (2014).

${ }^{8}$ MOGOLLÓN CANO-CORTÉS y PIZARRO GÓMEZ, Francisco Javier, La sillería de coro de la Catedral de Plasencia, Cáceres, Universidad de Extremadura, 1992, pp. 90 y ss.

9 TEIJEIRA PABLOS, María Dolores, "La sillería coral de Rodrigo Alemán en la catedral de Ciudad Rodrigo", en E. Azofra Agustín, La catedral de Ciudad Rodrigo. Visiones y Revisiones. Salamanca, Diputación Provincial, 2006, pp. 253-280.

${ }^{10}$ GARCIA MOGOLLÓN, Francisco Javier, La Catedral de Coria. Arcón de Historia y Fe, León, Edilesa, 1999, pp. 88 y ss.

${ }^{11}$ HEIM, Dorothee, "El retablo mayor de la Catedral de Toledo: Nuevos datos sobre la predela", Actas del Congreso Internacional sobre Diego de Siloé y la escultura de su época. (Burgos 13 al 16 de octubre de 1999), Burgos, Institución Fernán González, 2001, pp. 521-538.

12 ALONSO RUIZ, Begoña, "Los arquitectos de la Capilla Real de Granada", en L Ribot (coord.): Isabel la Católica y su época, Valladolid, Universidad de Valladolid, 2004, vol. II, pp. 1241-1261.

${ }^{13}$ MARTÍN MARTÍNEZ DE SIMÓN, Elena y PAYO HERNÁNZ, René Jesús, “La actuación de Francisco de Colonia en la iglesia de Nuestra Señora de Villahoz, Burgos”, en Begoña Alonso Ruiz (ed.): op. cit., pp. 149-
} 
sólo se sabe que la parroquia de Melgar ya estaba en 1528 abierta al culto ${ }^{14}$. El motivo aparece también en una ventana de la Casa de las Conchas de Salamanca, un edificio a caballo entre la estética gótica y la renacentista y que fue realizado, según los últimos estudios, entre 1494 y 1506 por artífices del círculo de Juan Guas, si no por el propio $\mathrm{Guas}^{15}$, y en otro edificio salmantino muy influido por éste. Que es el palacio de los Abarca, en Salamanca, obra realizada con posterioridad a 1492, en ella aparece el escudo de los Reyes Católicos con el blasón del Reino de Granada ${ }^{16}$.

La influencia burgalesa llegó a Sevilla en dos fases. La primera de ellas se inicia con la venida de Simón de Colonia en 1495 para trabajar en la catedral de Sevilla, tras ser llamado por el entonces arzobispo Diego Hurtado de Mendoza ${ }^{17}$. A Colonia se le atribuyen las trazas del cimborrio, la decoración de los hastiales del crucero y la capilla de la antigua de la catedral ${ }^{18}$, además de las del oratorio de la Casa de Pilatos ${ }^{19}$, dejándose sentir su influencia en algunas obras jerezanas ${ }^{20}$. Un segundo momento de llegada de maestros burgaleses a Sevilla viene tras la ruina del cimborrio, acaecida en 1511. Tras un periodo de incertidumbre en el que el Cabildo solicita los informes de diversos arquitectos, en 1513 es contratado como maestro mayor de la fábrica Juan Gil de Hontañón. Se ha señalado que los inicios profesionales de Gil de Hontañón están en la provincia de Segovia en pequeñas obras públicas y que su formación la realiza con el bretón Juan Guas, en las obras de la Cartuja madrileña del Paular ${ }^{21}$. Después desarrolla una amplísima carrera ligada a obras en la Meseta castellana norte y sur: Sigüenza, Alcalá de Henares, Medina del Campo, Palencia, Toledo, Almorox, Fuentepelayo, Baquerín, Belmonte de Campos, Coca y Tuérgano; así como trabaja al servicio de los duques del Infantado: Buitrago de Lozoya; y la familia Velasco: Santa Clara de Briviesca, Santa Clara de Medina de Pomar, el monasterio de la

157. APARICIO AHEDO, Óscar Ignacio, Las iglesias parroquiales del Bajo Arlanza. La iglesia parroquial de Villahoz, Burgos, Parroquia de Villahoz, 2012, pp. 27 y ss.

${ }^{14}$ HUIDOBRO SERNA, Luis, Apuntes para la historia de Melgar de Fernamental, Burgos, Diputación Provincial, 1947, pp. 43 y ss.

15 VASALLO TORANZO, Luis, "Rodrigo Maldonado de Talavera y la casa de las Conchas", en Begoña Alonso Ruiz (ed.): op. cit., pp. 159-173.

16 GALLEGO DE MIGUEL, Amalia, Los doctores de la reina y su casa en Salamanca, Salamanca, Centro de Estudios Salmantinos, 1972, pp. 45 y ss.

${ }^{17}$ GESTOSO Y PÉREZ, José, Sevilla monumental y artística, Sevilla, El Conservador, 1908, vol. II, p. 41.

18 JIMÉNEZ MARTÍN, Alfonso, "Las fechas de las formas" en Alfonso Jiménez Martín (ed.): La catedral gótica de Sevilla, Sevilla, Universidad de Sevilla, 2006, pp. 103 y ss.

${ }^{19}$ MEYER, August, El estilo gótico en España, Madrid, Espasa Calpe, 1929. p. 30.

${ }^{20}$ ROMERO BEJARANO, Manuel, "Y Burgos llegó a Jerez. Simón de Colonia y Juan Gil de Hontañón en la arquitectura jerezana de comienzos del XVI”, en Arquitectura y diseño de la ciudad desde el siglo XVI hasta Isabel II, Actas de las I Jornadas de Historia del Arte en Jerez, Jerez, 2014, pp. 17-53.

21 ALONSO RUIZ. Begoña, "Juan Gil de Hontañón en Segovia: sus inicios profesionales", en Boletín del Seminario de Estudios de Arte y Arqueología, no 66 (2000), pp. 153-162. 
Vid, atruyéndosele San Francisco de Medina de Rioseco ${ }^{22}$. Mantenemos ciertas discrepancias con la vinculación de Gil de Hontañón con la escuela de Toledo y considero que sus obras, al menos sus intervenciones en Sevilla y en las iglesias del Arzobispado, así como en Salamanca, están directamente vinculadas con el círculo de cantería de Burgos y su renovación ornamental. En este sentido, Castro Santamaría ha señalado las semejanzas entre las capillas hornacinas de la catedral de Salamanca y la de la sacristía de los Cálices de la Catedral de Sevilla, parecidos que justifica por la presencia en ambas fábricas de unos mismos maestros canteros ${ }^{23}$. Aunque no hay constancia documental de la intervención de Juan Gil en la sacristía sevillana, la autora no va desencaminada, pues ambas obras acusan la influencia de la escuela de Burgos.

Juan Gil de Hontañón se encargó del diseño del nuevo cimborrio de la Magna Hispalensis, si bien su paso por la catedral se ha puesto en relación con la construcción del sector meridional de las capillas de los alabastros, el trasaltar mayor y con un posible proyecto para la Sacristía de los Cálices. En este sentido, Morales Martínez ve la huella del maestro en la obra construida y le atribuye los pilares adosados, el enmarque interior de la entrada y el arco solio del testero, basándose en analogías formales con obras de la catedral de Salamanca y las capillas de los alabastros de la hispalense ${ }^{24}$. Precisamente en una de estas capillas, la dedicada a La Anunciación, la decoración de una taca repite el modelo ornamental del gablete de cinco lados que analizamos en esta ponencia. En fechas recientes se ha señalado la influencia de Juan Gil en algunas obras jerezanas de las primeras décadas del $\mathrm{XVI}^{25}$, sopesándose la posibilidad de que el maestro diese trazas para algunos edificios durante algunas de sus estancias en Sevilla. En este caso se encuentra la parroquia de San Miguel $^{26}$ y su capilla bautismal, cuya portada nos ha servido de referencia. Sin embargo, en esta obra también se aprecia la influencia del tardogótico portugués, pues entre los baquetones aparece un elemento ornamental propio del arte luso del momento, como es

22 CORTÓN DE LAS HERAS, María Teresa, La construcción de la Catedral de Segovia, Segovia, Caja de Ahorros de Segovia, 1990, pp. 126-171.ALONSO RUIZ, Begoña, "El cimborrio de la Magna Hispalense y Juan Gil de Hontañón”, en Actas del IV Congreso Nacional de Historia de la Construcción. (Cádiz 27 al 29 de enero de 2005), Madrid, Instituto Juan de Herrera, 2005, pp. 21-33. LÓPEZ DÍEZ, María de la Blanca, Los Trastámara en Segovia. Juan Guas maestro de las obras reales, Segovia, Caja de Segovia, 2006, pp. 71-72. ALONSO RUIZ, Begoña y JIMÉNEZ MARTÍN, Alfonso, La traça de la iglesia de Sevilla, Taller Dereçeo, Sevilla, 2009, pp. 162-166.

${ }_{23}$ CASTRO SANTAMARÍA, Ana, "La Catedral de Sevilla como modelo: la catedral de Salamanca", en JIMÉNEZ MARTÍN, Alfonso. (ed.): La catedral sin catedral. Actas de la XVIII edición del Aula Hernán Ruiz, Taller Dereçeo, Sevilla, 2011, pp. 71-72.

${ }^{24}$ MORALES MARTÍNEZ, Alfredo José, La Sacristía Mayor de la Catedral de Sevilla, Diputación Provincial, Sevilla, 1984, pp. 185-186.

${ }^{25}$ ROMERO BEJARANO, Manuel, Maestros y Obras, Op. Cit., 2014, pp. 17-53.

${ }^{26}$ ROMERO MEDINA, Raúl y ROMERO BEJARANO, Manuel, "Burgos, Jerez y Salamanca. Juan Gil de Hontañón y su influencia en la parroquia de San Miguel de Jerez de la Frontera", en Mariano Hernández Casas (coord.) La Catedral de Salamanca. De Fortis a Magna, Salamanca, Salamanca, Diputación de 2014, pp. 2033-20146. 
una soga anudada cuajada de cascabeles. Trataremos de dar una explicación a esta extraña coincidencia. Pero antes veremos cómo el motivo del remate pentagonal importado de Castilla continuó viajando por Andalucía hasta Málaga y Almería.

Durante el episcopado de Diego Ramírez de Villaescusa (1500-1518) la sede de Málaga comenzaba las primeras obras de envergadura realizadas en canteria ${ }^{27}$. En este sentido, la más relevante fue la portada tardogótica levantada en la mezquita aljama de Málaga, llamada a convertirse en catedral poco tiempo después. Se trata de una obra aislada, que tenía como pretensión dotar de una entrada monumental a la mezquita (se cree fue abierta en la base de su alminar), hoy incorporada a la iglesia del Sagrario, para la que se ha propuesto una cronología de entre 1514 y $1528^{28}$. El modelo de portada sigue las soluciones similares burgalesas, puesto que incorpora la estructura pentagonal mixtilínea que resulta una especie de gablete formado por cuatro molduras semicirculares, decoradas en su parte exterior con cardinas y en su interior por las mismas flores con hojas similares al cardo. Aunque la obra se ha puesto en relación con el círculo de Enrique Egas, pensamos que su traza debe vincularse a esa segunda llegada de maestros burgaleses a Sevilla y, concretamente, al maestro Juan Gil de Hontañón. De hecho, son notables las similitudes de esta portada con la fachada de la epístola de la iglesia de Santa María la Real de Aranda de Duero. En Almería volvemos a encontrar el mismo motivo de gablete pentagonal en la puerta que da salida al claustro de su catedral (Ilustración n ${ }^{\circ}$ 4). El 22 de septiembre de 1522 la ciudad sufrió un brutal terremoto que derribó por completo la primitiva catedral, que se había edificado sobre la antigua mezquita. La construcción del nuevo templo se realiza en un nuevo solar bajo el episcopado de Fray Diego de Villalán, quien puso la primera piedra el 4 de octubre de $1524^{29}$. Se ha propuesto la posible autoría de los Egas para la nueva iglesia, aunque en el edificio no se encuentran elementos formales que lo puedan relacionar con las obras de estos maestros. Pese a que no hay una cronología clara para esta portada, pensamos que debe datarse entre 1524 y 1535 y vincularla a las citadas formas burgalesas. De hecho en la girola del propio templo encontramos la capilla funeraria del obispo Villalán, de planta centralizada en lo que parece ser una versión de las espectaculares capillas castellanas diseñadas por los Colonia como la del Condestable de la catedral de Burgos.

\footnotetext{
27 SUBERBIOLA MARTÍNEZ, Jesús, "Fundación y dotación de iglesias en la diócesis de Málaga tras la conquista (1487-1540)”, en El Arte de la Iglesia de Málaga. Málaga, 1998, pp. 26-29.

${ }^{28}$ Ibídem.

29 LÓPEZ MARTÍN, Juan, "La catedral fortaleza", en Luminaria. Dos milenios de cristianismo en Almería. Almería, Obispado de Almería, 2007, pp. 68-70.
} 


\section{LA AVENTURA PORTUGUESA. DESDE BURGOS A GOA}

Las relaciones de la Fábrica de la Catedral de Sevilla con Portugal fueron frecuentes durante todo el proceso constructivo ${ }^{30}$. Éstas vinieron determinadas tanto por el aprovisionamiento de piedras como por el tránsito de maestros canteros ${ }^{31}$. El vecino reino estaba bien conectado por barco a través del puerto de Sevilla y con un viento favorable la distancia entre Sevilla y Lisboa podía cubrirse en dos jornadas. Las relaciones se intensifican por este motivo a partir de 1496, cuando la fábrica afrontaba su etapa final y Alonso Rodríguez ocupaba el cargo de maestro mayor. Ello tendrá consecuencias mayores pues, dado que en Portugal había una gran actividad constructiva repartida en diversos talleres de cantería, se comprende que los maestros se desplazaron allí buscando obras y trabajadores. De este modo se estrecharon las relaciones artísticas. En 1507 las nóminas recogen a dos canteros de origen portugués. Uno es Carauallo ${ }^{32}$, que actúa como asentandor del taller de cantería y el otro Francisco de Segovia, quien realiza tareas como entallador y que se ha supuesto que es Francisco de Segovia Validés, portugués, que está activo en 1522 en Belém junto a Juan de Montoya y Aparicio de Ramales. Con toda probabilidad estos maestros trabajaron activamente en el taller sevillano, colaborando en las labores decorativas que Juan Gil de Hontañón dirigía en el cimborrio y en las capillas de los alabastros, junto con Diego de Riaño quien, al marchar a Lisboa en 1517, huyendo por dar muerte a un cantero, pudo llamarles para colaborar en la efervescente fábrica de Belém ${ }^{33}$.

Pero la clave de este asunto se localiza en las nóminas sevillanas del 16 de octubre de 1507, donde figura un maestro llamado Castillo y que, semanas más tarde, es denominado como Juan del Castillo. Este maestro procedía de Arnuero, Cantabria, y se presume que pudo llegar al taller catedralicio de Burgos entre 1487 y 1488 convirtiéndose en poco tiempo en el brazo derecho del maestro Simón de Colonia, a quien pudo acompañar a la citada junta de maestros celebrada en el taller catedralicio de Sevilla en 1496. El nombramiento de Simón de Colonia como maestro mayor pudo provocar que Juan del Castillo permaneciera en Sevilla, de manera definitiva o de modo intermitente, incluso después de que el burgalés dejara el cargo. La formación de este maestro es

\footnotetext{
30 ROMERO MEDINA, Raúl y ROMERO BEJARANO, Manuel, "La Catedral de Sevilla y su conexión con la arquitectura del tardogótico portugués”, en Alfonso Jiménez Martín, La Catedral entre 1434 y 1517: bistoria y conservación. Sevilla, Taller Dereçeo, 2013, pp. 237-276.

31 RODRÍGUEZ ESTÉVEZ, Juan Clemente, "Los canteros de la obra gótica de la Catedral de Sevilla (14331528)", en Laboratorio de Arte, no 9 (1996), p. 70.

32 JIMÉNEZ MARTÍN, Alfonso, "Las fechas de las formas", op. cit., p. 96.

33 MORALES MARTÍNEZ, Alfredo José, "Diego de Riaño en Lisboa", en Arcbivo Español de Arte, no 264 (1993), pp. 404-408.
} 
netamente burgalesa y ello se explica por el pleno dominio de las nervaduras, carácter plano de las bóvedas, la profusa decoración leñosa y el empleo de sofisticados caireles, entre otros. Esto deja entrever que Castillo pudo ser el que puso en ejecución, junto a Alonso Rodríguez, o incluso en solitario, los proyectos sevillanos de Simón de Colonia. Parece que Juan del Castillo se ganó pronto la confianza del maestro mayor Alonso Rodríguez, como lo prueba el hecho de que en 1506 lo nombre como fiador en su testamento ${ }^{34}$. Así las cosas, es más que probable que Juan del Castillo realizase viajes con su maestro mayor para supervisar la extracción de piedra de Portugal. El 24 de mayo de 1508 la documentación recoge un pago a Alonso Rodríguez de 4.800 maravedíes de "su yda a Setúbal”, Se ha especulado con la posibilidad de que, aprovechando este viaje, Juan del Castillo se afincara en Portugal y no regresará a Sevilla ${ }^{36}$. Allí concluyó la capilla mayor de la iglesia del convento de Jesús en Tomar y en 1509 se le contrató para realizar el nuevo ábside de la catedral de Braga, la primera obra cubierta con combados en Portugal ${ }^{37}$. A partir de ahí, el maestro desarrolló una fulgurante carrera en el vecino reino con el nombre de João de Castillo, lo que explicaría las posteriores conexiones lusas con Sevilla y, yendo aún más allá, con Burgos. Esto explica que el gablete pentagonal que nos ocupa aparezca con relativa frecuencia en la arquitectura portuguesa de las primeras décadas del XVI. Así, está presente en las principales obras del momento, como el monasterio de jerónimos de Belem, en Lisboa, la fachada de la iglesia conventual de Santa Cruz de Coimbra, donde está en las capillas del crucero, en el convento de Cristo de Tomar, ya que aquí se encuentra en los estribos de la iglesia o el retablo mayor de la catedral de Braga. El modelo tuvo cierta difusión aparecen en obras secundarias y así se puede ver en la portada principal de la iglesia matriz de Golega, la iglesia de Santa Maria de Marvila de Santarem, la fachada de la Casa Consistorial de Olivenza, la iglesia matriz de Freixo de Espada a Cinta, o la iglesia conventual de Madre Deus de Lisboa. Incluso llegó a calar en la arquitectura popular, como demuestra una ventana del pequeño pueblo de Linhares da Beira, perdido en la Sierra da Estrela.

\footnotetext{
${ }^{34}$ LÓPEZ MARTÍNEZ, Celestino, Arquitectos, escultores y pintores vecinos de Sevilla, Sevilla, Rodríguez Giménez y Compañía, 1928, pp. 171-172.

35 JIMÉNEZ MARTÍN, Alfonso, "Las fechas de las formas", op. cit., p. 97.

36 Pese a que la historiografía portuguesa ya contempla esta posibilidad desde hace muchos años (CORREIA, Víctor, As obras de Santa Maria de Belem, Lisboa, Tipografía do Anuario Comercial, 1922, p. 16), la más reciente, y un tanto exagerada, biografía del maestro (EALO DE SA, María, El arquitecto Juan del Castillo. El constructor del Mundo, Santander, Colegio Oficial de Arquitectos de Cantabria, 2009) hace caso omiso de las evidencias y aún haciéndole pasar por mil y un lugares en los que resulta literalmente imposible que estuviera, no menciona su estancia en Sevilla.

${ }^{37}$ NUNES DA SILVA, Ricardo, op. cit., pp. 527 y ss.
} 
La expansión marítima de Portugal hizo que el gablete surcase los mares hasta tierras muy lejanas, pero también hubo un importante movimiento de maestros portugueses hacia la Baja Andalucía, en especial hacia Jerez y su entorno ${ }^{38}$, de ahí que quepa la posibilidad de que el modelo burgalés llegase a la jerezana parroquia de San Miguel de vuelta del país vecino. Durante el reinado de Manuel I (1495-1521), O Bem Aventurado, Portugal vive una auténtica Edad de Oro. Durante su mandato, en 1498, Vasco de Gama descubre la ruta marítima atlántica hacia la India y, en 1505, Francisco de Alameida se convierte en el primer virrey de las tierras recién conquistadas. Del mismo modo, el almirante Alfonso de Alburquerque aseguraba el monopolio del país luso en las rutas marítimas del Océano Índico, que se convirtió en un "lago portugués" 39 . Así las cosas, Portugal estableció puertos comerciales en lugares tan lejanos como Goa, Malaca, las Islas Molucas, Macao o Nagasaki. Estas ciudades necesitaban ser dotadas con una nueva arquitectura de la que carecían, pues la mayoría de las construcciones estaban realizadas en madera y barro, debida a la mano de maestros locales, aunque en un primer momento pudieron ser reaprovechadas antiguas mezquitas islámicas o templos hindúes tras su debida purificación y consagración ${ }^{40}$. No olvidemos que muchas de estas ciudades, como Goa, habían pertenecido al sultanato de Delhi, si bien luego, hasta la conquista de Portugal, pasaron a formar parte del Imperio Vijayanagara. Situada en la costa occidental de la India, Goa, tras ser conquistada por Alfonso de Alburquerque en 1510, pasó a ser el centro de la India portuguesa y Virreinato portugués de Asia, cuya jurisdicción comprendía India, Malaca, Indonesia, Timor oriental, el Golfo Pérsico, Macao en China y las bases comerciales en el Imperio del Sol Naciente. Además, Goa se convierte en la nueva Lisboa y centro de una diócesis (que establecía su jurisdicción por casi todo el Oriente, al incluir desde el Cabo de Buena Esperanza hasta China y Japón) fundada, el 31 de enero de 1533, por el papa Clemente VII mediante la Bula Romani Pontificis Circumspectio ${ }^{41}$.

El Virreinato y Diócesis de Goa necesitó de la mano de maestros canteros que supieran trazar y levantar edificios religiosos y militares en cantería. Hemos de suponer que muchos maestros tardogóticos iniciaran un largo viaje desde los focos constructivos más fervientes de Portugal (Lisboa, Batalha, Tomar y Braga) hasta la India, muy probablemente

\footnotetext{
${ }^{38}$ ROMERO BEJARANO, Manuel, Obras y Maestros, op.cit., pp. 45-90.

39 Sobre el imperio portugués se pueden consultar las obras de RUSSELL WOOD, A. J. R., The Portuguese Empire 1415-1808. John Hopkins University Press, 1998 y SUBRAHMANYAM, S., The Portuguese Empire in Asia, 1500-1700: A Political and Economic History. Wiley-Blackwell, 2012

40 Pero Días recoge varios testimonios de la impresión que causaron estas edificaciones locales en los padres misioneros que llegaron a Goa. DIAS, Pero, Historia da Arte portuguesa no mundo (1415-1822). O espaço do Indico. Estella. Círculo de Leitores, 1998, p. 66.

${ }^{41}$ BISPO, "Goa como centro de jurisdição eclesiástica nas Índias Orientais e o significado arquitetônico e histórico-musical de sua Sé Catedral”, en Revista Brasil-Europa: Correspondência Euro-Brasileira no 131/12 (2011).
} 
apoyados por el monarca Manuel I. De hecho, son varios los maestros que se registran con el título de "mestre das obras de el-rei na India", un cargo que fue creado al efecto ${ }^{42}$. En 1515 tenemos las primeras noticias sobre obras en marcha, como la iglesia de Santa Catalina de Alejandría, un templo de tres naves con crucero y tres capillas abovedadas por cabecera, con coro a los pies y dotada de puerta monumental y torre ${ }^{43}$. Su traza ha sido atribuida al maestro Tomás Fernández ${ }^{44}$, que era natural de Vila Ruiva, una pequeña feligresía portuguesa situada en el concejo de $\mathrm{Cuba}^{45}$, pues ya en 1506 figuraba como maestro de obras del rey en India ${ }^{46}$. No sabemos si puede tratarse del maestro de la torre de la Catedral de Lisboa que aparece documentado como tasador de unas casas en la ciudad lisboeta en febrero de 1502 ${ }^{47}$. En 1509 trabajó como maestro de obras en Cochim y en 1510 construyó la fortaleza de Velha Goa ${ }^{48}$. Su nombre aparece ligado a las obras de varias fortalezas construidas a lo largo del océano índico: Coachim, Canador, Pangim, Calecut, Socotorá y Ormuz $^{49}$. Entre 1523 y 1531 residía de nuevo en su localidad natal ${ }^{50}$.

Por esta misma época se debieron iniciar las obras de la iglesia del Rosario, también conocida como iglesia del Priorato Velho, cuya cabecera conserva una bóveda de crucería estrellada con terceletes y combados ${ }^{51}$. Asimismo, otras fábricas diocesanas hoy ya desaparecidas como Nuestra Señora da Serra, en la que fue enterrado en primera instancia el virrey Alfonso de Alburquerque, la iglesia de Santa María Magdalena o la iglesia de Nuestra Señora de la Luz ${ }^{52}$.

Junto con las obras diocesanas, las Órdenes religiosas, llegadas en los primeros años de la conquista de Goa, también emprendieron importantes fábricas. En este sentido, destaca el convento de San Francisco de Asís, que se convirtió en la casa madre de la Orden Franciscana en Oriente, que fue fundado en 1518 por Fray Antonio Louro ${ }^{53}$. Las obras se iniciaron en la segunda década del siglo XVI, colocándose la primera piedra el 2 de

42 SOUSA VITERBO, Francisco, Dicionário histórico e documental dos arquitectos, engenbeiros, e construtores portugueses. Lisboa, 1988, V. I, p. 347.

${ }^{43} \mathrm{Al}$ menos esta es la descripción que da del proyecto Fray Domingo de Sousa, Vicario General en Goa, al rey de Portugal. Cit. DA SILVA REGO, Antonio, Documentaçao para a História das Missoes do Padroado Portugués do Oriente. Índia. Lisboa, 1947-1958, V. I., p. 252.

44 NUNES PEREIRA, Antonio, A Arquitectura religiosa Crista de Velha Goa. Segunda metade do Século XVIPrimeiras Décadas do Século XVII. Lisboa, Fundaçao Oriente, 2005, p. 82.

${ }^{45}$ MOREIRA, Rafael, A Arquitectura do Renascimiento no Sul de Portugal. Lisboa, 1991, p. 361.

46 SOUSA VITERBO, Francisco, op. cit., pp. 347-355.

${ }^{47}$ Ibidem. v. III. p. 312.

48 Ibidem. v. I. pp. 347-355.

${ }^{49}$ Ibidem.

${ }^{50}$ MOREIRA, Rafael, A Arquitectura do Renascimiento no Sul de Portugal. Lisboa, 1991, p. 161.

${ }^{51}$ MOREIRA, Rafael, "From Manueline to Renaissance in Portuguese India", Mare Liberum, no. 9 (1995), p. 406.

${ }^{52}$ DIAS, Pedro, op. cit. pp. 67 y ss.

53 TRINDADE, Pero da, Conquista spiritual de Oriente. Lisboa, Centro de Estudios Históricos Ultramarinos, 1964, pp. 127-128. 
febrero de $1520^{54}$. Se ha especulado con que su traza pudo ser dada en Portugal ${ }^{55}$, si bien esto parece improbable si tenemos en cuenta que la documentación ha arrojado nombres de maestros portugueses que trabajaron en Goa. En este sentido, Nunes Pereira ${ }^{56}$ le atribuye la traza al maestro Manuel de la Ponte que ejerció el cargo de maestro de obras del rey en India entre $1517-1525^{57}$. A este maestro le sucede Leonardo Vaz, quien lo ejerció entre 1525 y 1527, que había trabajado bajo la supervisión de Juan del Castillo en las obras del refectorio del monasterio de Belén, hacia $1517^{58}$. No por casualidad aparece también en India Juan de la Puente ${ }^{59}$, hermano de Manuel de la Puente, que puede ser el mismo maestro trasmerano que se documenta trabajando en las Casas Capitulares de Sevilla, de diciembre de 1527 a diciembre de 1528 y de junio de 1532 a agosto de $1533^{60}$. Habría que plantear la hipótesis que los de la Puente pudieran ser compatriotas cántabros de Juan del Castillo, que junto con Lorenzo Vaz habían trabajado bajo sus órdenes en Portugal y, posteriormente, habrían pasado a India. Aquí encontramos otro camino de vuelta a la Baja Andalucía, ya que en el Cabildo sevillano también se pueden apreciar elementos propios del tardogótico portugués, tales como soportes entorchados, decoración floral en los laterales de los nervios o una portada, la de la Sala Capitular, cuyo esquema repite la del palacio Sub Ripas de Coimbra.

Posteriores noticias documentales nos informan cómo en 1526 fue puesto en pregón una obra de refuerzo de los muros de la iglesia. En este contexto, Lorenzo del Vaz y Juan de la Puente dieron su parecer sobre la obra, que fue rematada en el maestro Joao Fernández, al que la documentación denomina morador en Goa ${ }^{61}$. Un año más tarde, el 10 de abril de 1527, se le pagaba al cantero Sebastiao o Bastiam Pires por haberse ocupado de obras en los tejados de la nave y capilla mayor de la iglesia, bajo la supervisión de Lorenzo Vaz, así como en diversas dependencias del monasterio, entre la que se encontraba el tejado de los dormitorios de los frailes ${ }^{62}$. De la obra original, que fue renovada en 1661 ya como templo jesuita, perdura una portada (Ilustración $n^{\circ}$ ) cuya composición nos remite a las formas burgalesas que venimos señalando, ya que presenta la estructura de gablete

\footnotetext{
54 SCHURHAMMER, "Carta inédita sobre a fundaçao do Convento de San Francisco de Goa", Boletín do Instituto Vasco de Gama, no. 74 (1957), pp.58-59.

${ }^{55}$ DIAS, Pedro, op. cit.

${ }^{56}$ NUNES PEREIRA, Antonio, op. cit., p. 85.

${ }^{57}$ Sousa Viterbo le atribuye un origen italiano aunque no sabemos en qué fundamenta esta hipótesis. SOUSA VITERBO, Francisco, op. cit., v. II, p. 333.

${ }^{58}$ Está documentado en las obras de Belén a partir de 1514. MOREIRA, Rafael, "From Manueline", op. cit., p. 403. Aunque la obra del refectorio data de 1517. SOUSA VITERBO, Francisco, op. cit. v. III, p. 165.

${ }^{59}$ SOUSA VITERBO, Francisco, op. cit., v. II, pp. 332-333.

${ }^{60}$ MORALES MARTÍNEZ, Alfredo José, "El ayuntamiento de Sevilla: maestros canteros, entalladores e imagineros", en Laboratorio de Arte, no. 4 (1991), p. 65.

${ }^{61}$ Cit. DA SILVA REGO, op. cit., V. I., p. 90-94.

${ }^{62}$ Ibídem, pp. 102, 103 y 105.
} 
pentagonal estudiado. Se trata de una portada de gran riqueza decorativa con soluciones ornamentales y motivos decorativos directamente inspirados en las empresas marítimas lusas. Centrando el conjunto se ubica, sobre la clave del arco, un fondo que guarda un blasón, del que penden sendos astrolabios esféricos o bolas armilares, símbolos marítimos de las expediciones lusas. Abajo la portada arranca con tres baquetones, a ambos lados, en los que se incluye decoración naturalista. Por último vemos cómo la portada presenta la reinterpretación del gablete pentagonal de Burgos, y justifica el viaje que hicieron las formas del último gótico desde las frías tierras castellanas a las cálidas de Goa, en India.

\section{A MODO DE CONCLUSIÓN}

La escuela de cantería del tardogótico burgalés presenta formas decorativas singulares que evolucionan rápidamente del gótico al renacimiento en la década de los años 20 del siglo XVI. En este sentido, el tipo de decoración de vano formado por un gablete pentagonal, objeto de este estudio, se observa en varios de los ejemplos citados en tierras burgalesas. Si bien algunas sillerías de coro castellanas a finales del siglo XV presentan con anterioridad estas mismas formas decorativas, es en Burgos donde se da por primera vez en decoraciones de cantería, al margen de esa "mazoneria" de sillas de coro.

Un hecho que ha quedado probado es la movilidad de los maestros canteros que se agrupaban en auténticas redes de trabajo con lazos de solidaridad y parentesco. Esta situación explica que los modelos de Burgos llegaran a Sevilla, donde la construcción de su catedral demandaba maestros responsables de su taller de cantería. Este fenómeno no sólo queda probado a principios del siglo XVI, sino que ya desde la conquista de la ciudad, en pleno siglo XIII, los maestros de Burgos están presentes en la renovación y/o construcción de las mezquitas en nuevas iglesias cristianas. En el siglo XVI la influencia burgalesa llega a Sevilla en dos fases, la primera de la mano de Simón de Colonia, hijo del arquitecto alemán instalado en Burgos a partir de 1440, y la segunda traída por Juan Gil de Hontañón, sin duda, uno de los maestros que más fama y reputación alcanzaría en Castilla. Será de la mano de este maestro cuando las formas se difundan por la baja Andalucía, bien en obras cuya traza pudo dar o bien en otras muy directamente ligadas con los maestros que pudo formar. En este sentido, una de las hipótesis sobre el viaje de estas formas por tierras peninsulares sería desde Burgos directamente a Andalucía en ciudades como Sevilla, Jerez, Málaga o Almería, 
La segunda hipótesis que barajamos es que estas formas pudiesen pasar antes por Portugal y luego extenderse por la baja Andalucía. De hecho, en el ejemplo de San Miguel de Jerez de la Frontera esta hipótesis cobra más fuerza a juzgar por la decoración lusa que ofrece su portada del baptisterio. Así las cosas, maestros que se formaron en Burgos, como Juan del Castillo, tras una vinculación inicial con el taller de cantería de Sevilla, pasarían a trabajar a Portugal formando a maestros locales en estas formas castellanas aprendidas. Las relaciones entre Sevilla y Portugal han quedado probadas no sólo a nivel comercial sino en relación con el aprovisionamiento de piedra y el trasiego de maestros de obras. Cuando Portugal deja de ser activa en talleres como los de Lisboa, Batalha, Tomar o Braga, los portugueses acuden a una pujante Andalucía ávida de obras en marcha. Es en estos momentos cuando las experiencias de Burgos se funden con los motivos lusos dando lugar a ejemplares como los de la iglesia de San Miguel, en Jerez de la Frontera.

Junto a ello, la segunda salida de maestros portugueses se va a realizar hacia tierras del Índico, donde Portugal había establecido puertos comerciales después de la firma del tratado de Tordesillas. Así las cosas, hemos probado la presencia de maestros lusos en lugares como Goa, que se establece como virreinato y diócesis y cuyas mezquitas del sultanato de Delhi tienen que ser reemplazadas por nuevas fábrica ad hoc para el culto cristiano. A pesar de que muchas de las fábricas que se debieron construir fueron transformadas, y otras simplemente no han llegado hasta nuestros días, el ejemplo en pie de la portada de la iglesia de San Francisco de Goa, luego templo jesuita, nos remite a ese mismo esquema decorativo de gablete pentagonal originario de Burgos con decoraciones lusas.

En definitiva, este trabajo prueba la difusión de las formas decorativas tardogóticas en cantería desde Burgos a otros lugares de la península ibérica como Andalucía y Portugal. Del mismo modo, establece una hipótesis sobre si las formas viajaron primeramente de Burgos a Andalucía y luego a Portugal o desde Burgos a Portugal y luego a Andalucía. Por último, prueba la presencia de estas mismas formas en la India gracias a la difusión portuguesa. A falta de nuevas hipótesis que demuestren lo contrario, es Portugal la que parece difundir las formas tanto en Andalucía como en la India. 


\section{Ilustraciones}

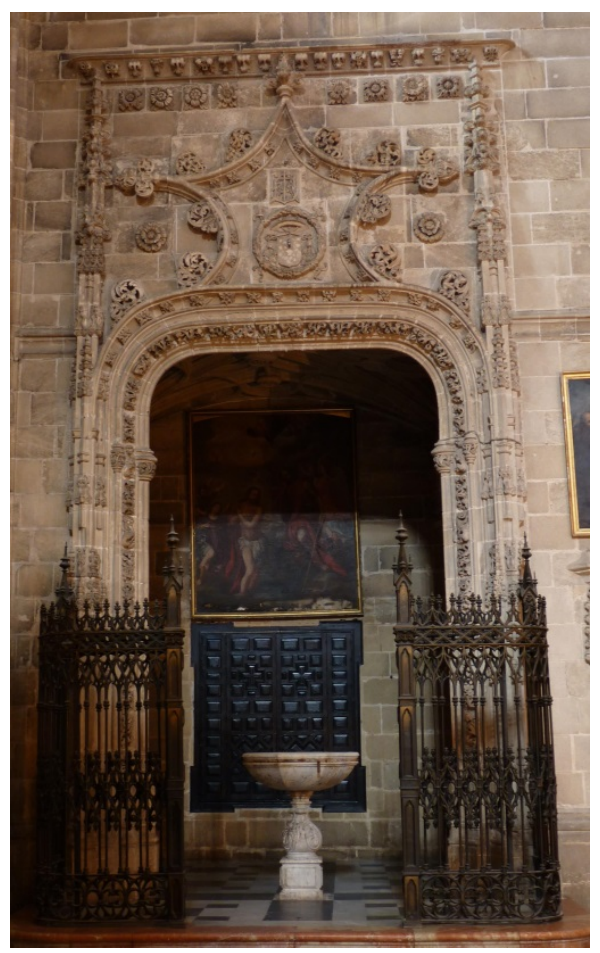

Ilustración 1. Portada de la Capilla Bautismal. Parroquia de San Miguel. Jerez de la Frontera. Foto Romero Bejarano.

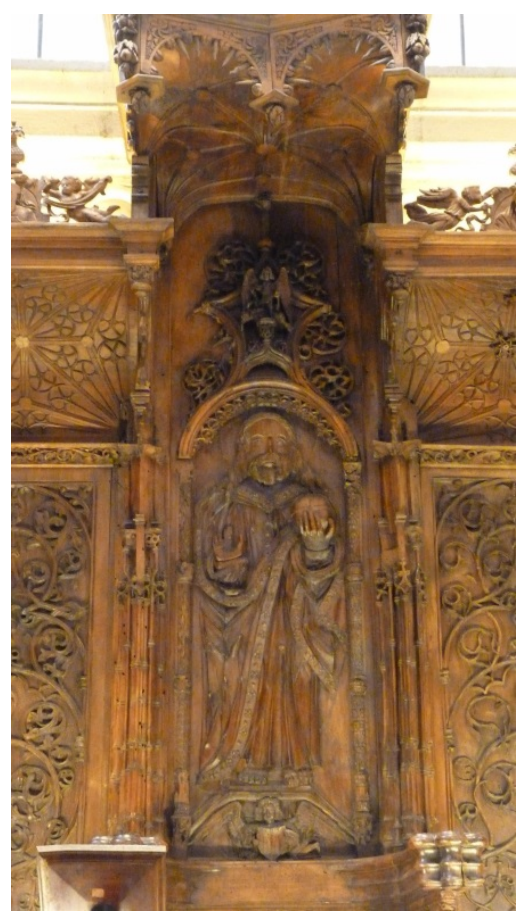

Ilustración 2. Sitial del Obispo. Sillería Coral. Catedral de Coria. Foto Romero Bejarano. 


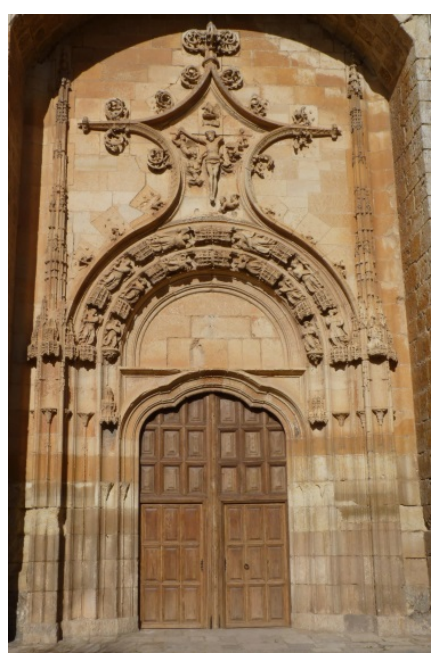

Ilustración 3. Portada. Parroquia de Nuestra Señora de la Asunción. Melgar de Fernamental, Burgos. Foto Romero Bejarano.

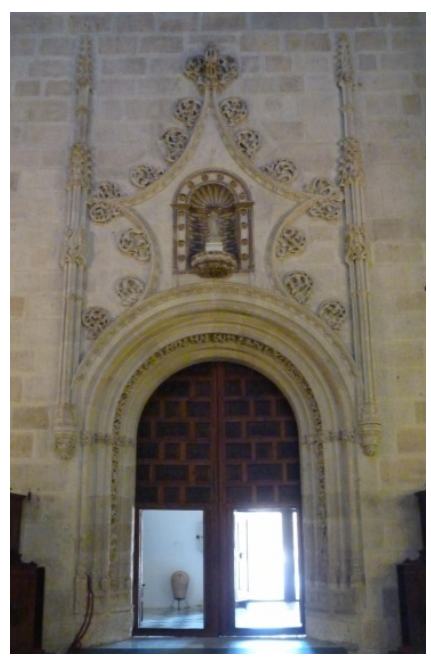

Ilustración 4. Portada del Claustro. Catedral de la Encarnación. Almería. Foto Romero Bejarano. 


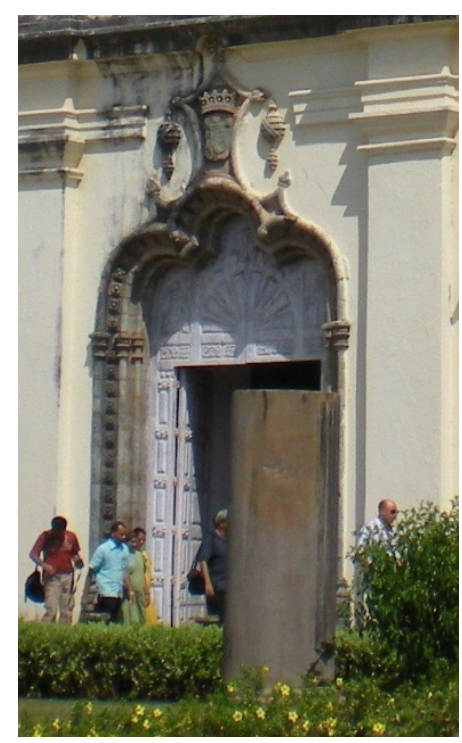

Ilustración 5. Portada. Iglesia de San Francisco. Goa, India. Foto Nunes Pereira. 